\title{
Téoros
}

Revue de recherche en tourisme

\section{Congrès / foires}

\section{Valérie Théberge}

Volume 15, numéro 3, automne 1996

\section{Le tourisme d'affaires}

URI : https://id.erudit.org/iderudit/1075071ar

DOI : https://doi.org/10.7202/1075071ar

Aller au sommaire du numéro

\section{Éditeur(s)}

Université du Québec à Montréal

\section{ISSN}

0712-8657 (imprimé)

1923-2705 (numérique)

Découvrir la revue

Citer ce document

Théberge, V. (1996). Congrès / foires. Téoros, 15(3), 56-56.

https://doi.org/10.7202/1075071ar d'utilisation que vous pouvez consulter en ligne.

https://apropos.erudit.org/fr/usagers/politique-dutilisation/ 


\section{B I B L I O G R A P I I E \\ CONGRÈS / FOIRES}

Valérie Théberge, bibliothécaire

Centre de documentation touristique UQAM-ACTA

American Express. (1984)

Sondage American Express sur les voyages d'affaires canadiens 1994 1995. S.L: American Express:

BLANCHET, Martin. (1995)

Centre de congrès, centre de

foires... Montréal:

Université du Québec à Montréal.

CAZELAIS, Normand. (1995)

Etrangers d'ici et d'ailleurs, Tome II, Montréal: XYZ Éditeur.

CAZELAIS, Normand. (1994)

Séminaire hébergement touristique et congrès. Montréal:

Université du Québec à Montréal.

COMMISSION CANADIENNE DU TOURISME. "s.d." Business

Travel Program. Ottawa:

Communication canadienne du tourisme.

(1996) Conventions and Meetings Canada 1996-1997. Markham:

Effective Communications.

DÉPATIE, RAYMOND, BOUCHARD, GABRIEL. (1996)

Évaluation des retombées

économiques résultant des activités tenues au Palais des congrès de Montréal. Québec:

Tourisme Québec.

E.G.A. Inc. (1996)

Salons, expositions, congrès: guide événements d'affaires 1997-1997.

Toronto: E.G.A. Inc.

FRANCE MEETINGS AND

INCENTIVES. (1995) Guide du

tourisme d'Affaires. Paris: Varennes

Entreprises SARL.

FRÉCHETTE, Micheline. (1993)

Le rayonnement géographique

du tourisme et des congrès à

Montréal. Montréal:

Université du Québec à Montréal.
(1996) Guide événements d'affaires 1996-1997. Ile-des-Soeurs:

Guide événements d'affaires.

HÉBERT, Gilles. (1992)

La mesure du tourisme et le proble. me de la double comptabilisation du tourisme d'affaires. Sherbrooke:

Université de Sherbrooke.

ISOGROUP. (1994)

Stratégie du développement du produit touristique québécois de calibre international. Montréal: Isogroup.

KPMG. (1996)

Etude du potentiel sur le marché des congrès majeurs et des foires. Sommaire à l'intention des dirigeants. Rapport final. S.L.: KPMG.

MINISTĖRE DU TOURISME. (1993) Stratégie de mise en marche touris. tique du Québec 1993-1996. Québec:

Ministère du Tourisme du Québec.

NYSTRAND, Julia. (1994)

Outlook for Business Travel. S.L.:

National Geographic Traveler.

\section{OFFICE DES CONGRESS ET \\ DU TOURISME DU GRAND \\ MONTREAL. (1995)}

L'état du tourisme à Montréal. Bilan des années 1994. Montréal:

Office des congrès et du tourisme du grand Montréal.

\section{OFFICE DES CONGRES ET \\ DU TOURISME DU GRAND \\ MONTREAL. (1995)}

Analyse des marchés touristiques pour Montreal: fiches syntheses. Montréal:

Office des congrès et du tourisme du grand Montréal.
OFFICE DES CONGRĖS ET DU TOURISME DU GRAND MONTRÉAL (1996)

Guide du planificateur 1997. Montréal:

Office des congrès et du tourisme du grand Montréal.

\section{OFFICE DU TOURISME ET DES CONGRESS DE LA COMMUNAUTÉ URBAINE DE QUÉBEC. (1994) Liste des congrès, salons et voyages-motivation. Québec: Office du tourisme et des congrès de la Communauté urbaine de Québec.}

PICARD, Alain. (1996)

Portrait des facteurs de choix d'un site à congrès. Sherbrooke: Université de Sherbrooke.

(1995) Portfolio of Canadian Resorts: Meetings and Conference Facilities Planner 1996.

Toronto: Maclean Hunter.

(1994) Répertoire des établissements de réunions et congrès au Québec 1994-1995. Montréal: Ed. Globe Magazine.

(1995) The Meetings \& Incentive Planner's Resource. Seacaucus: Reed Travel Group.

(1994) Tourisme d'affaires, voyages de motivation, tourisme d'agrément au Québec. Montréal:

Société d'édition de la revue Forces.

TOURISME ET CONGRÈS DE BEAUCE. (1993)

Tourisme d'affaires, congrès et réunions d'affaires. Saint-Georges: Tourisme et congrès de Beauce.

TOURISME QUÉBEC. (1996)

Meetings in Quebec for

Unconventional Success. Québec: Tourisme Québec. 